Marquette University

e-Publications@Marquette

$12-20-2013$

\title{
Comment on "Synthesis, Characterization, and Structures of Persistent Aniline Radical Cation": It Is a Protonated Aniline and Not an Aniline Radical Cation
}

\author{
Marat R. Talipov \\ Marquette University \\ Jeewantha S. Hewage \\ Marquette University \\ Sergey V. Lindeman \\ Marquette University, sergey.lindeman@marquette.edu \\ James R. Gardinier \\ Marquette University, james.gardinier@marquette.edu \\ Rajendra Rathore \\ Marquette University
}

Follow this and additional works at: https://epublications.marquette.edu/chem_fac

Part of the Chemistry Commons

\section{Recommended Citation}

Talipov, Marat R.; Hewage, Jeewantha S.; Lindeman, Sergey V.; Gardinier, James R.; and Rathore, Rajendra, "Comment on "Synthesis, Characterization, and Structures of Persistent Aniline Radical Cation": It Is a Protonated Aniline and Not an Aniline Radical Cation" (2013). Chemistry Faculty Research and Publications. 563.

https://epublications.marquette.edu/chem_fac/563 
Marquette University

e-Publications@Marquette

\title{
Chemistry Faculty Research and Publications/College of Arts and Sciences
}

This paper is NOT THE PUBLISHED VERSION.

Access the published version at the link in the citation below.

Angewandte Chemie International Edition, Vol. 53, No. 4 (January 21, 2014): 938-942. DOI. This article is (C) Wiley and permission has been granted for this version to appear in e-Publications@Marquette. Wiley does not grant permission for this article to be further copied/distributed or hosted elsewhere without the express permission from Wiley.

\section{Comment on "Synthesis, Characterization, and Structures of Persistent Aniline Radical Cation": It Is a Protonated Aniline and Not an Aniline Radical Cation}

\author{
Marat R. Talipov \\ Department of Chemistry, Marquette University, Milwaukee, Wisconsin \\ Jeewantha S. Hewage \\ Department of Chemistry, Marquette University, Milwaukee, Wisconsin \\ Sergey V. Lindeman \\ Department of Chemistry, Marquette University, Milwaukee, Wisconsin \\ James R. Gardinier \\ Department of Chemistry, Marquette University, Milwaukee, Wisconsin \\ Rajendra Rathore \\ Department of Chemistry, Marquette University, Milwaukee, Wisconsin
}


We thank the National Science Foundation for financial support and Qadir K. Timerghazin for helpful discussions. The calculations were performed on the high-performance computing cluster Père at Marquette University funded by NSF awards OCI-0923037 and CBET-0521602.

\section{Abstract}

The same, but different: The reaction of tri-tert-butylaniline (TBA) with $\mathrm{AgSbF}_{6}$ in $\mathrm{CH}_{2} \mathrm{Cl}_{2}$ produces a greencolored intermediate which undergoes decomposition to form a protonated aniline $\left(\mathrm{TBAH}^{+} \mathrm{SbF}_{6}{ }^{-}\right)$. Crystals of the protonated aniline salt (see picture) were analyzed by X-ray diffraction and found to have the same crystal characteristics as the crystals of the supposed cation radical first identified in 2012.

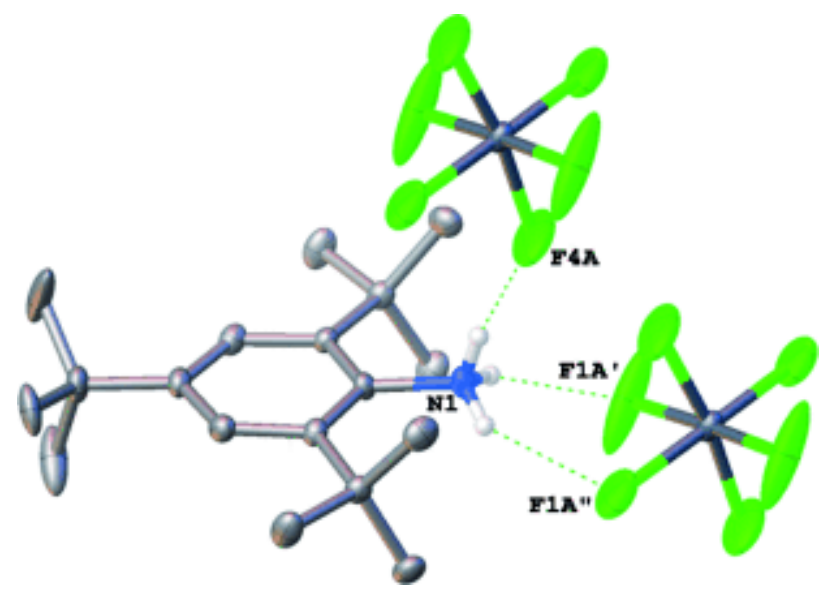

In a recent publication, ${ }^{1}$ Chen et al. have claimed the isolation of a persistent radical-cation salt derived from 2,4,6-tri-tert-butylaniline (TBA) by its prolonged $(\approx 24 \mathrm{~h})$ reaction with equimolar $\mathrm{AgSbF}_{6}$ in dichloromethane at ambient temperatures with $>80 \%$ yield. They have determined the structure of this radical-cation salt by singlecrystal X-ray crystallography at $123 \mathrm{~K}\left(-150^{\circ} \mathrm{C}\right)$ and found that this radical cation exhibits a long $\mathrm{C}_{\mathrm{Ar}}$ ? $\mathrm{N}$ bond length of $1.496 \AA$. They have also claimed that the aromatic ring in the crystalline radical cation undergoes a temperature-dependent transformation from a bisallyl to a quinoidal geometry, while the $\mathrm{C}_{\mathrm{Ar}}$ ? $\mathrm{N}$ bond length remained largely unaffected (see structures below).

\section{Quinoidal Structure}

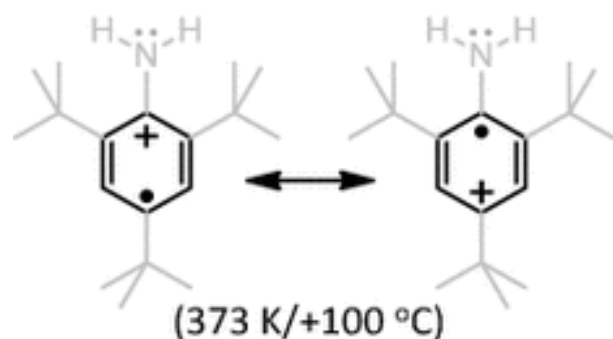

Bisallyl Structure

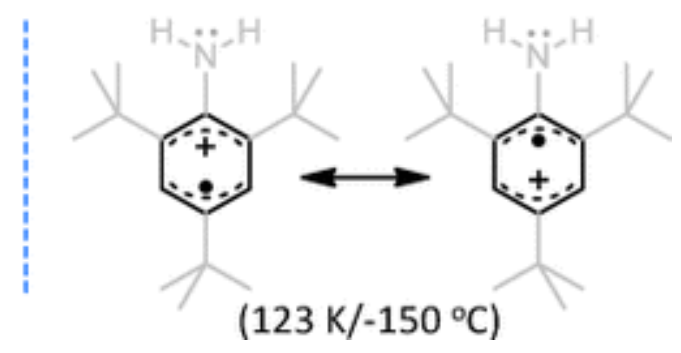

This highly unusual crystallographic observation in $\mathrm{TBA}^{+}$. was reconciled by ab initio calculations using an unrestricted MP2 method. Based on our extensive experience with organic cation radicals, ${ }^{2}$ this finding was highly troubling because of the lack of involvement of the nitrogen lone pair in stabilizing the cationic aryl group (i.e. long $\mathrm{C}_{\mathrm{Ar}}$ ? $\mathrm{N}$ bond) and the fact that the electronic reorganization of aromatic ring required such high temperatures (i.e. $+100^{\circ} \mathrm{C}$ ).

In order to understand this highly unusual finding, we have redetermined the single-crystal X-ray structure of this supposed TBA salt at different temperatures and now unequivocally show that it is protonated aniline 
and not an aniline radical cation. Below, we carefully outline various experimental and computational missteps that led these authors ${ }^{1}$ to incorrectly identify this salt.

\section{X-Ray Crystallography}

Following closely the procedure of Chen et al., ${ }^{1}$ a solution of neutral TBA (102 mg, $\left.0.39 \mathrm{mmol}\right)$ in anhydrous dichloromethane $(60 \mathrm{~mL})$ was treated with $\mathrm{AgSbF}_{6}(129 \mathrm{mg}, 0.38 \mathrm{mmol})$ in an inert atmosphere at $22^{\circ} \mathrm{C}$, and the resulting green solution was stirred for $24 \mathrm{~h}$. Afterwards, the green-colored mixture was filtered under an inert atmosphere, concentrated to a volume of roughly $3 \mathrm{~mL}$ and stored in an air-tight flask at $-10{ }^{\circ} \mathrm{C}$ in a refrigerator. After several hours, the solution produced a well-formed crop of single crystals that were analyzed by X-ray crystallography.

An X-ray-quality crystal laced with light-green liquid (see Figure S1 in the Supporting Information) was cut off from a larger crystal and the data collection was carried out with Mo radiation at $100 \mathrm{~K}$ as well as at 123, 173, 223 , and $273 \mathrm{~K}$. The cell dimensions for this crystal as well as the anomalous (negative) thermal expansion coefficient along the $a$ axis above $123 \mathrm{~K}$ were practically identical to those reported in Ref. ${ }^{1}$ (see Tables S1 and S2 in the Supporting Information). ${ }^{3}$

The structure was solved in the same non-centrosymmetric space group $P m n 2_{1}$ as reported in Ref. ${ }^{1}$ with both the cation and anion positioned over the crystallographic mirror plane. After anisotropic refinement, the thermal ellipsoids of the $\mathrm{F}$ atoms of the anion and carbon atoms of para-tert-butyl groups demonstrated a large anisometry that required introducing a suitable disorder model and placing some restrictions on the thermal ellipsoids. ${ }^{4}$ The positions of hydrogen atoms at the nitrogen were found from a difference Fourier series with two peaks of approximately $0.5 \mathrm{e}^{-} \AA^{-3}$, where one was positioned on the mirror plane while the other was located outside the plane. The subsequent full refinement without restrictions (except those from crystallographic symmetry) on either coordinates or the isotropic temperature parameters of the hydrogens resulted in almost perfect tetrahedral geometry of the nitrogen atom with reasonable values of N?H bond lengths and thermal parameters $\left(U_{\text {iso }}\right)$ for the hydrogen atoms. The same model was used to refine the structure at all temperatures except $273 \mathrm{~K}$, where the deteriorating quality of the dataset due to the larger thermal motion forced the refinement of the $\mathrm{NH}_{3}{ }^{+}$group with fixed standard $\mathrm{N}$ ? $\mathrm{H}$ distances. Importantly, in all structures obtained at different temperatures, the three hydrogen atoms form $\mathrm{H}$-bonding contacts with $\mathrm{F}$ atoms of the $\mathrm{SbF}_{6}{ }^{-}$anion - with one $\mathrm{H} \cdots \mathrm{F}$ contact above the molecular plane and the other two $\mathrm{H} \cdots \mathrm{F}$ contacts below it (see Figure 1).

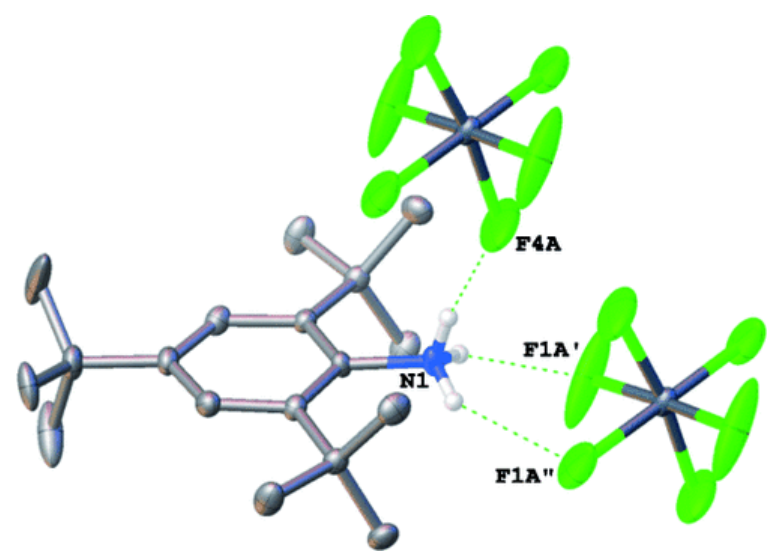

Figure 1. The $\mathrm{X}$-ray structure of $\mathrm{TBAH}^{+} \mathrm{SbF}_{6}{ }^{-}$showing $\mathrm{H} \cdots \mathrm{F}$ contacts between the $\mathrm{NH}_{3}{ }^{+}$group and the surrounding $\mathrm{SbF}_{6}{ }^{-}$anions. Disordered atoms and the rest of the hydrogen atoms are omitted for clarity. 
Table 1 summarizes selected bond lengths of $\mathrm{TBAH}^{+} \mathrm{SbF}_{6}{ }^{-}$, obtained from our experiments, at various temperatures as well as the bond lengths reported in Ref. ${ }^{1}$. In our crystallographic experiments, the bond lengths in the aromatic ring and $\mathrm{C}_{\mathrm{Ar}}$ ? $\mathrm{N}$ bond vary only by $2-3 \sigma$ from $100 \mathrm{~K}$ to $273 \mathrm{~K}$ and are rather insensitive to the temperature changes - a result which is in sharp contrast to that reported in Ref. ${ }^{1}$ (Table 1 ).

Table 1. A comparison of the selected bond lengths of $\mathrm{TBAH}^{+}$(see structure below) from our experiments and those reported by Chen et al. ${ }^{1}$ in square brackets at different temperatures.

[a]

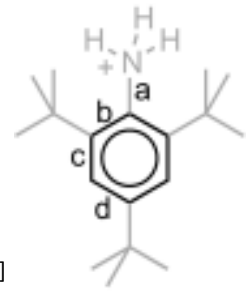

\begin{tabular}{|c|c|c|c|c|c|c|c|}
\hline Bond & $\begin{array}{l}\text { Temperature } \\
{[\mathrm{K}]}\end{array}$ & & & & & & \\
\hline & $100 \mathrm{~K}$ & $123 \mathrm{~K}$ & $173 \mathrm{~K}$ & $223 \mathrm{~K}$ & $273 K$ & $323 \mathrm{~K}$ & $373 \mathrm{~K}$ \\
\hline$a$ & $1.473(5)-^{[b]}$ & $\begin{array}{l}1.468(5) \\
{[1.496(7)]}\end{array}$ & $\begin{array}{l}1.474(5) \\
-^{[b]}\end{array}$ & $\begin{array}{l}1.479(6) \\
{[1.480(12)]}\end{array}$ & $\begin{array}{l}1.480(7) \\
{[1.470(16)]}\end{array}$ & $\overline{[b]}[1.490(15)]$ & $-^{[b]}[1.51(2)]$ \\
\hline$b$ & $1.400(3)-^{[b]}$ & $\begin{array}{l}1.403(3) \\
{[1.381(4)]}\end{array}$ & $\begin{array}{l}1.402(3) \\
{ }_{-}^{[b]}\end{array}$ & $\begin{array}{l}1.399(4) \\
{[1.385(7)]}\end{array}$ & $\begin{array}{l}1.402(4) \\
{[1.390(11)]}\end{array}$ & $-^{[b]}[1.400(9)]$ & $\begin{array}{l}- \\
{[b]} \\
{[1.404(13)]}\end{array}$ \\
\hline c & $1.390(4)--^{[b]}$ & $\begin{array}{l}1.395(4) \\
{[1.423(5)]}\end{array}$ & $\begin{array}{l}1.403(4) \\
-[b]\end{array}$ & $\begin{array}{l}1.393(4) \\
{[1.415(9)]}\end{array}$ & $\begin{array}{l}1.389(5) \\
{[1.408(12)]}\end{array}$ & $\begin{array}{l}- \\
{[\mathrm{b}]} \\
{[1.369(11)]}\end{array}$ & $-\overline{[b]}[1.281(15)]$ \\
\hline$d$ & $1.389(4)--^{[b]}$ & $\begin{array}{l}1.394(3) \\
{[1.387(5)]}\end{array}$ & $\begin{array}{l}1.389(4) \\
{ }^{[b]}\end{array}$ & $\begin{array}{l}1.393(4) \\
{[1.388(7)]}\end{array}$ & $\begin{array}{l}1.394(5) \\
{[1.390(11)]}\end{array}$ & $-^{[b]}[1.410(9)]$ & $-\overline{[b]}[1.452(13)]$ \\
\hline
\end{tabular}

[a] The $R 1$ factors based on the "observed" reflections (with $>2 \sigma$ ) for our X-ray structures varied from 3.02 to $4.52 \%$ upon increasing temperatures. Although the corresponding structures in Ref. ${ }^{1}$ had a similar range of $R$ factors (from 2.73-5.92\%), they were based on half the number of experimental observations ( $2924 I>2 \sigma$ in our study vs. 1406 I>2 $\sigma$ in Ref. ${ }^{1}$ at $123 \mathrm{~K}$ ) which results in less precise geometries. [b] Not measured.

In order to reconcile these drastic differences between the results of our experiments and those reported in Ref. 1 , we make following critical observations.

1. The crystal structures obtained in this study have same cell parameters/cell volume/space group/temperature-dependent variations in the $a$ axis of the crystal as those reported in Ref. ${ }^{1}$. However, our crystal structure solution showed that it contains disordered $\mathrm{SbF}_{6}{ }^{-}$anions as well as one of the tert-butyl groups, while the X-ray structure solution in Ref. ${ }^{1}$ claimed that the structure was completely ordered. In our extensive experience with X-ray crystallography, we find it to be highly unlikely that the crystals of a given material with the same cell dimensions/space group/etc. will form both ordered and disordered crystals. ${ }^{5}$

2. We deliberately prepared the protonated TBA cation salt $\mathrm{TBAH}^{+} \mathrm{SbF}_{6}{ }^{-}$, using the procedure outlined in Ref. ${ }^{1}$ and obtained colorless single crystals at $-10^{\circ} \mathrm{C}$ from a dichloromethane solution as above. A crystallographic analysis of a single crystal of the deliberately prepared $\mathrm{TBAH}^{+} \mathrm{SbF}_{6}{ }^{-}$revealed that it has identical cell parameters/space group/structure solution/disorder/etc. with those obtained for the pale-green crystals prepared from the reaction of TBA with $\mathrm{AgSbF}_{6}$ (i.e. Figure 1 and Table 1). ${ }^{6}$

3. We also established the uniformity of the bulk samples of the green crystals and the deliberately prepared colorless crystals of $\mathrm{TBAH}^{+} \mathrm{SbF}_{6}{ }^{-}$by their powder diffraction pattern (see Figure $\mathrm{S} 2$ in the Supporting Information), which clearly showed that both the samples consist of largely $\mathrm{TBAH}^{+} \mathrm{SbF}_{6}{ }^{-}$. 
4. Table 1 clearly shows that in our crystallographic experiments the bond lengths in the aromatic ring do not show significant alterations as well, as they do not undergo significant changes when the temperature is increased.

Thus, the crystallographic results presented above clearly suggest that the crystal structure reported by Chen et al. ${ }^{1}$ is not of the TBA cation radical but of the protonated TBA cation. Next, we examine the various other experimental/computational factors that have led these authors ${ }^{1}$ to incorrectly characterize this TBA salt.

\section{Electrochemistry and UV/Vis Spectroscopy}

Cyclic voltammetry of TBA in dichloromethane in the presence of $n \mathrm{Bu}_{4} \mathrm{~N}^{+} \mathrm{PF}_{6}{ }^{-}$as the supporting electrolyte showed reversible oxidation waves at different scan rates ranging from $50-500 \mathrm{mV} \mathrm{s}^{-1}$ (Figure $2 \mathrm{~A}$ ). Although these results support $\mathrm{TBA}^{+}$. formation in the electrochemical oxidation of TBA, it should be noted that the observation of reversible cyclic voltammograms for a given molecule only suggest that its ion-radical intermediate is stable at the electrochemical time scale (i.e. microseconds to milliseconds). ${ }^{7}$ Thus, the premise of Chen et al. ${ }^{1}$ concerning the prolonged stability of $\mathrm{TBA}^{+}$. based on cyclic voltammetry experiments is the initial misstep that led to the mistaken identification of the TBA salt.

A
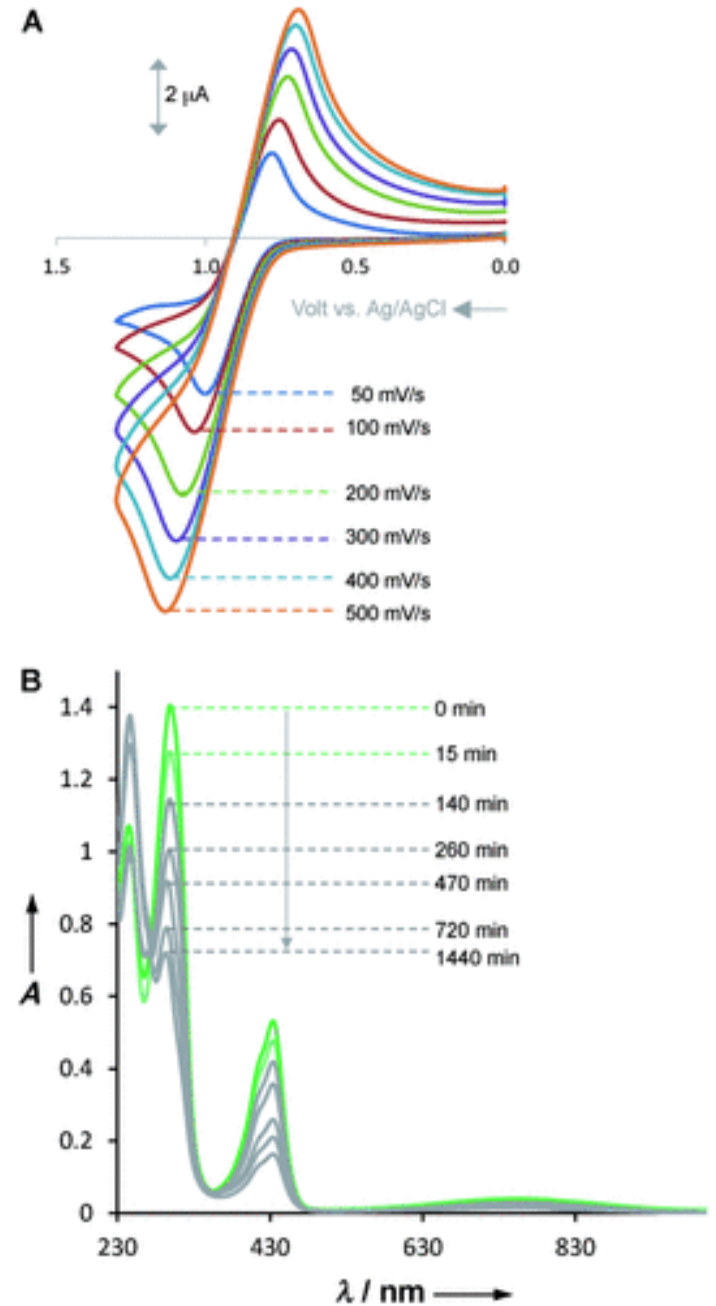

Figure 2. A) Cyclic voltammograms of $0.2 \mathrm{mM}$ TBA in dichloromethane containing $0.2 \mathrm{M} \mathrm{nBu}_{4} \mathrm{~N}^{+} \mathrm{PF}_{6}{ }^{-}$at different scan rates (indicated) and under an argon atmosphere at $22^{\circ} \mathrm{C}$. B) Absorption spectra of aliquots of the green reaction mixture (i.e. $\mathrm{TBA}+\mathrm{AgSbF}_{6}$ in $\mathrm{CH}_{2} \mathrm{Cl}_{2}$ ) showing that it decomposes slowly during the course of $24 \mathrm{~h}$. 
In order to monitor the stability of a green-colored solution of TBA cation radical, aliquots of the reaction mixture of TBA and $\mathrm{AgSbF}_{6}$ in anhydrous dichloromethane at $22^{\circ} \mathrm{C}$ were collected at several reaction times and monitored by UV/Vis spectroscopy. The initially formed green-colored species attains a maximum concentration after about $15 \mathrm{~min}$, and then slowly decomposes over $24 \mathrm{~h}$ (Figure $\mathbf{2 ~ B ) . ~}{ }^{8}$ Therefore, the spectroscopic observations in Figure $\mathbf{2}$ attest to the instability of TBA cation radical which undergoes decomposition leading to products such as a labile hydrazine derivative ${ }^{8 b}$ and protonated aniline. It is highly likely that the pale green crystals of $\mathrm{TBAH}^{+} \mathrm{SbF}_{6}{ }^{-}$acquire their color simply due to the adsorption of colored impurities present in the reaction mixture. Indeed, such a thesis strongly corroborates the observation of a rather weak ESR signal from a solution of green crystals, as reported in Ref. ${ }^{1}$.

\section{Computational Studies}

In order to rationalize the mistaken observations of the unusual geometry of $\mathrm{TBA}^{+}$. with the long $\mathrm{C}_{\mathrm{Ar}}$ ? $\mathrm{N}$ bond length (ca. $1.49 \AA$ ) and its temperature-dependent conversion from the bisallyl to the quinoidal form, Chen et al. ${ }^{1}$ turned to computational studies, using unrestricted versions of various density functional theory (DFT) methods (B3LYP, M06-2X, CAM-B3LYP, and $\omega B$ 97X-D) as well as an ab initio second-order Møller-Plesset perturbation theory (MP2) method with double-zeta basis sets. However, their initial attempts showed that without a counterion $\mathrm{TBA}^{+}$. has the expected quinoidal geometry with a short $\mathrm{C}_{\mathrm{Ar}}$ ? $\mathrm{IN}$ bond length (ca. $1.34 \AA$ ) .

Unfortunately, these authors ${ }^{1}$ ignored this initial computational red flag and forged ahead based on their thesis that the observed bisallyl geometry of $\mathrm{TBA}^{+}$. in its X-ray structure was due to the crystal environment. Indeed, they obtained the desired bisallyl geometry for the complex [TBA $\left.\left(\mathrm{SbF}_{6}\right)_{2}\right]^{--}$by employing the unrestricted MP2 method (UMP2). However, calculations of open-shell systems with the UMP2 method can be extremely unreliable if the reference unrestricted Hartree-Fock (UHF) wavefunction suffers from significant spin contamination. ${ }^{9}$ Spin contamination, an artificial admixture of higher spin states into the wavefunction, can be quantified by the deviation of the expectation value of the total spin-squared operator $S^{2}$ from its expected value for the given spin multiplicity, that is, $\left\langle S^{2}\right\rangle=0.75$ for a doublet state. ${ }^{9}$ In UMP2 calculations of $\left[\mathrm{TBA}\left(\mathrm{SbF}_{6}\right)_{2}\right]^{--}$reproduced following Ref. ${ }^{1}$, we found $\left\langle S^{2}\right\rangle=1.36$, which renders the results of such calculations nearly meaningless. Thus, the resulting bisallyl geometry is likely a computational artifact. Indeed, the geometry optimizations of $\left[\mathrm{TBA}\left(\mathrm{SbF}_{6}\right)_{2}\right]^{-}$using DFT methods always yielded the quinoidal structure, with virtually no spin contamination, $\left\langle S^{2}\right\rangle=0.750-0.751$, in accord with the expectation that the DFT methods provide much more robust description of open-shell systems than UMP2 method. ${ }^{10}$

In order to generate support for the temperature-induced transformation of TBA ${ }^{+}$from a bisallyl to a quinoidal isomer, Chen et al. ${ }^{1}$ resorted to single-point UMP2 calculations using the geometries form the X-ray structures at 123 and $373 \mathrm{~K}$, respectively. Their analysis (in Figure 5, Ref. ${ }^{1}$ ) claims that highest occupied molecular orbitals obtained with UMP2 satisfactorily rationalize the observation of bisallyl and quinoidal geometries. Notwithstanding the severe spin contamination issues of these UMP2 calculations, the use of X-ray geometries for these calculations is expected to simply regurgitate the bias imposed on this computational analysis. In fact, a closer look at these computational results showed that they are also marred with numerous (obvious) slip-ups. For instance, Figure 5 of Ref. ${ }^{1}$ presents UHF molecular orbitals, not UMP2 orbitals as claimed; in fact, the UMP2 method can generate only natural orbitals (i.e. eigenfunctions of the one-electron density matrix), but not canonical molecular orbitals. Moreover, these UHF orbitals are shown for $\alpha$-electrons only, while the significantly different orbitals from the $\beta$-manifold are not shown (for full details, see the Supporting Information). 
A complete molecular orbital picture generally allows one to predict the structural distortions in cation radicals by a simple visual inspection of the bonding versus nonbonding regions of the molecular orbitals. ${ }^{11}$ Indeed, when the UHF $\alpha$ and $\beta$ molecular orbitals of the bisallyl structure (from X-ray geometry at $123 \mathrm{~K}$ ) are considered together, they actually predict that the structure should adopt a quinoidal geometry (see further details in the Supporting Information).

Chen et al. ${ }^{1}$ rationalized, based on the natural bond orbital (NBO) analysis, that the unusually elongated $\mathrm{C}_{\mathrm{Ar}}$ ? $\mathrm{P} \mathrm{N}$ bond (ca. $1.49 \AA$ ) in $\mathrm{TBA}^{+}$arises due to electrostatic interactions with $\mathrm{SbF}_{6}{ }^{-}$anions that weaken $n \mathrm{~N} \rightarrow \pi^{*}$ interactions of the $\mathrm{N}$ atom with the aromatic ring. ${ }^{12}$ However, the results of NBO analysis in Ref. ${ }^{1}$ are misleading, as they only make use of the $\alpha$ orbitals which do not provide a complete picture of the electronic structure. ${ }^{13}$ In fact, in the $\beta$ manifold, the orbital interactions suggest the opposite effect which would lead to shortening of $\mathrm{C}_{\mathrm{A} r}$ ? $\mathrm{N}$ bond in TBA ${ }^{+}$.

Finally, one of the main causes of the erroneous finding by Chen et al. ${ }^{1}$ may have been stimulated by theoretical ${ }^{14}$ and experimental ${ }^{15}$ reports in support of bisallyl and quinoidal electronic structures for the benzenoid cation radicals owing to the Jahn-Teller effect. ${ }^{16}$ It is therefore important to reconsider the computation analysis of TBA cation radical in the context of Jahn-Teller effect as follows.

A degeneracy of the highest occupied molecular orbitals (HOMOs), for example, in a highly symmetrical benzene molecule, is essential for the Jahn-Teller effect to take place ${ }^{16}$ (Figure $3 \mathbf{A}$ ). Vertical removal of an electron from benzene gives rise to a conical intersection between quinoidal and bisallyl electronic states of the resulting cation radical, which, due to the Jahn-Teller effect, undergoes geometry relaxation to quinoidal or bisallyl structures (Figure $\mathbf{3} \mathbf{A}$ ).

A
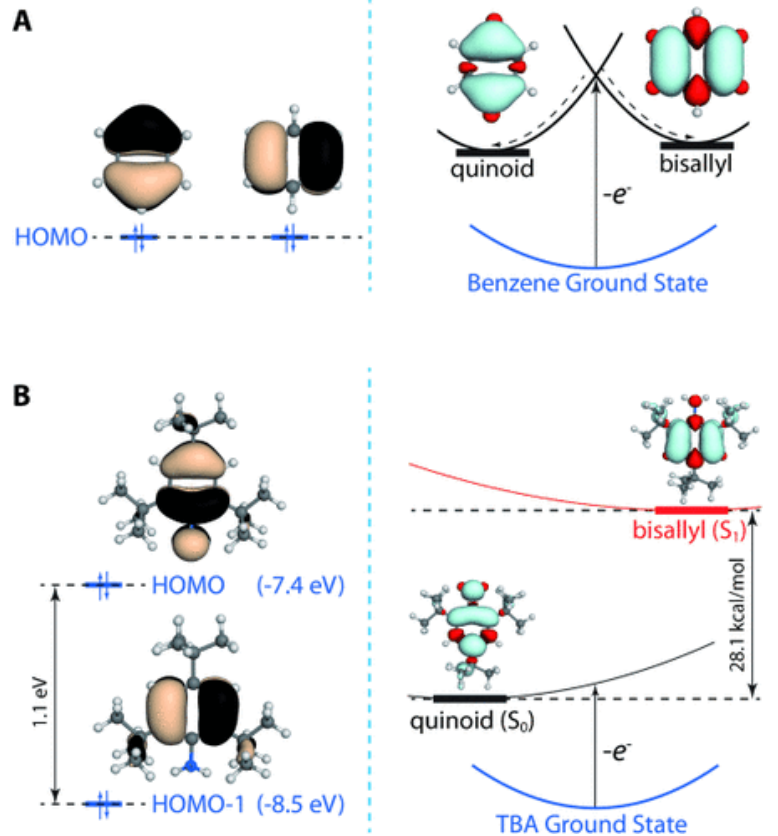

Figure 3. A comparison of the benzene cation radical, where the Jahn-Teller effect is manifested, and the TBA cation radical. The two highest occupied molecular orbitals of neutral benzene (A) and TBA (B) calculated at the HF/6-31G* level (left panel). The potential energy surfaces and spin densities of the corresponding cation radicals calculated at the B3LYP/6-31G* level (right panel).

The requirement of the degeneracy of the highest occupied molecular orbitals suggests that TBA ${ }^{+}$is not amenable to the Jahn-Teller effect (Figure $\mathbf{3}$ B). ${ }^{17}$ Strong coupling of the lone pair on nitrogen atom with one of the $\pi$ orbitals of benzene ring in TBA removes the degeneracy between HOMO and HOMO-1, which become 
separated by a $1.1 \mathrm{eV}$ energy gap. As a result, removal of an electron from the TBA HOMO leads to the quinoidal state, while the bisallyl state represents an excited state (Figure 3 A vs. B). We optimized the equilibrium geometries of both the ground-state quinoidal and excited-state bisallyl forms of TBA ${ }^{+}$at the B3LYP/6-31G* level (Figure $\mathbf{3}$ B; for full details see the Supporting Information), with a calculated energy difference between the two states of approximately $28 \mathrm{kcal} \mathrm{mol}^{-1} .{ }^{18}$ Because of this large energy gap, the bisallyl state cannot be reached without electronic excitation. Thus, a simple temperature change is not sufficient to cause an interconversion between a ground (quinoidal) to an excited (bisallyl) state.

\section{Conclusion}

The reaction of tri-tert-butylaniline (TBA) with $\mathrm{AgSbF}_{6}$ in $\mathrm{CH}_{2} \mathrm{Cl}_{2}$ produces a green-colored intermediate which undergoes decomposition to form a protonated aniline $\left(\mathrm{TBAH}^{+} \mathrm{SbF}_{6}{ }^{-}\right)$. The structure of the resulting $\mathrm{TBAH}^{+} \mathrm{SbF}_{6}{ }^{-}$was re-determined by X-ray crystallography. It was shown that our structure of $\mathrm{TBAH}^{+} \mathrm{SbF}_{6}{ }^{-}$has same cell parameters, space group, and negative thermal expansion as the crystals of the supposed cation radical incorrectly identified by the Chen et al. ${ }^{1}$ Moreover, we have demonstrated that a number of crystallographic and computational missteps led Chen et al. ${ }^{1}$ to incorrectly identify the protonated aniline as a cation-radical salt.

\section{References}

1 X. Chen, X. Wang, Y. Sui, Y. Li, J. Ma, J. Zuo, X. Wang, Angew. Chem. 2012, 124, 12048-12051; Angew. Chem. Int. Ed. 2012, 51, 11878- 11881.

2 2aT. S. Navale, K. Thakur, V. S. Vyas, S. H. Wadumethrige, R. Shukla, S. V. Lindeman, R. Rathore, Langmuir 2012, 28, 71-83; 2bR. Shukla, K. Thakur, V. J. Chebny, S. A. Reid, R. Rathore, J. Phys. Chem. B 2010, 114, 14592-14595; 2cM. Banerjee, V. S. Vyas, S. V. Lindeman, R. Rathore, Chem. Commun. 2008, 1889-1891; 2dM. Banerjee, S. V. Lindeman, R. Rathore, J. Am. Chem. Soc. 2007, 129, 8070-8071; 2eJ. K. Kochi, R. Rathore, C. Zhu, S. V. Lindeman, Angew. Chem. 2000, 112, 3817-3820; Angew. Chem. Int. Ed. 2000, 39, 3671- 3674.

3 It is noted that while particular $a, b$, and $c$ values show some variation (usual for different samples measured on different instruments with different software), the unit cell volume values show more consistency. The X-ray data for various structures reported in this paper are compiled in the Supporting Information (Table S1) and the cif files have been deposited with Cambridge Crystallographic Database. [CCDC 944685 (100 K, raj23j), 944686 (123 K, raj23j1), 944687 (173 K, raj23j2), 944688 (223 K, raj23j3), 944689 (273 K, raj23j4), and 944690 (100 K, raj23p)] contain the supplementary crystallographic data for this paper. These data can be obtained free of charge from The Cambridge Crystallographic Data Centre via www.ccdc.cam.ac.uk/data_request/cif.

4The disorder model has the tert-butyl group at the para position rotationally disordered equally over the crystallographic mirror plane. The $\mathrm{SbF}_{6}{ }^{-}$anion is rotationally disordered about two positions in a 2:1 ratio about the crystallographic mirror plane. At the latest stages of the refinement, all the carbonbonded hydrogen atoms were positioned geometrically riding on their pivot atoms, and methyl group hydrogens were allowed to rotate. The thermal parameters of $\mathrm{H}$ atoms were assigned depending on $U_{\text {iso/eq }}$ of their pivot carbon atoms $\left(1.2 U_{\text {iso/eq }}\right.$ for ring $\mathrm{H}$ atoms and $1.5 U_{\text {iso/eq }}$ for methyl $\mathrm{H}$ atoms).

5 We have consulted a number of expert X-ray crystallographers in the field concerning the likelihood of crystals of a given material with same cell dimensions/space group/etc. to form both ordered and disordered crystals and no example of such an occurrence was found.

6 Chen et al. ${ }^{[1]}$ reported a different modification of the crystals of $\mathrm{TBAH}^{+} \mathrm{SbF}_{6}{ }^{-}$and claimed that various bonds in $\mathrm{TBAH}^{+}$undergo a temperature-dependent lengthening. It is expected that the bond lengths should undergo shortening at higher temperatures because of the increased thermal motion, see: $\mathrm{V}$. Schomaker, K. N. Trueblood, Acta Crystallogr. Sect. B 1968, 24, 63- 76. It was unfortunate that Chen et al. ${ }^{[1]}$ obtained a different polymorph of deliberately prepared $\mathrm{TBAH}^{+}$than the supposed TBA cation 
radical crystals, which, in part, may have contributed to the erroneous identification of TBA cation radical.

7 A. J. Bard, L. R. Faulkner, Electrochemical Methods: Fundamentals and Applications, Wiley, New York, 2000.

8 8aB. Speicer, A. Rieker, S. Pons, J. Electroanal. Chem. Interfacial Electrochem. 1983, 147, 205- 222; 8bR. S.

Pilato, G. D. Williams, G. L. Geoffroy, A. L. Rheingold, Inorg. Chem. 1988, 27, 3665- 3668.

9 P. M. W. Gill, J. A. Pople, L. Radom, R. H. Nobes, J. Chem. Phys. 1988, 89, 7307- 7314.

10 J. Baker, A. Scheiner, J. Andzelm, Chem. Phys. Lett. 1993, 216, 380- 388.

11 Note that HOMO-1 in Figure 3 B may look like a "quinoidal" form but it will produce a "bisallyl" like geometry in the cationic state, see the Supporting Information for full details.

12 Coulombic considerations alone would suggest that the presence of $\mathrm{SbF}_{6}{ }^{-}$anions would affect the localization of the cationic charge on the nitrogen atom and would lead to an enhanced $n N \rightarrow \pi^{*}$ interactions and the shortening of the $\mathrm{C}$ ? $\mathrm{N}$ bond.

13 P. M. Wojciechowski, W. Zierkiewicz, D. Michalska, P. Hobza, J. Chem. Phys. 2003, 118, 10900- 10911.

14 B. E. Applegate, T. A. Miller, J. Chem. Phys. 2002, 117, 10654- 10674.

15 H. Shorafa, D. Mollenhauer, B. Paulus, K. Seppelt, Angew. Chem. 2009, 121, 5959- 5961; Angew. Chem. Int. Ed. 2009, 48, 5845- 5847.

16 16aH. A. Jahn, E. Teller, Proc. R. Soc. London Ser. A 1937, 161, 220- 235; 16bA. J. Johansson, J. Chem. Educ. 2012, 89, 63- 69.

17Coexistence of the degenerate bisallyl and quinoidal electronic structures of TBA ${ }^{+\cdot}$ is implausible even from simple steric considerations. It is expected that a quinoidal electronic structure of TBA ${ }^{+.}$will be stabilized in comparison to the bisallyl structure owing to elongation of $\mathrm{C} 1$ ? $\mathrm{C} 2$ and $\mathrm{C} 1$ ? $\mathrm{C} 6$ bonds thereby providing relief from steric repulsion between 1-amino group and the adjacent bulky 2,6-tert-butyl substituents.

18The bisallyl structure on the first excited singlet electronic state was also reproduced using M06-2X and $\omega B 97 X-D$ functionals, with the similar energy gap of 31 and $29 \mathrm{kcal} \mathrm{mol}^{-1}$, respectively. Our additional calculations show that the energy gap between quinoidal and bisallyl states will only be increased if the crystal environment is taken into account (see the Supporting Information for details). 